UCRL-ID-122067

\title{
Low Frequency Electromagnetic Signals from Underground Explosions - On-Site Inspections Research Progress Report
}

\author{
J. J. Sweeney
}

July 21, 1995

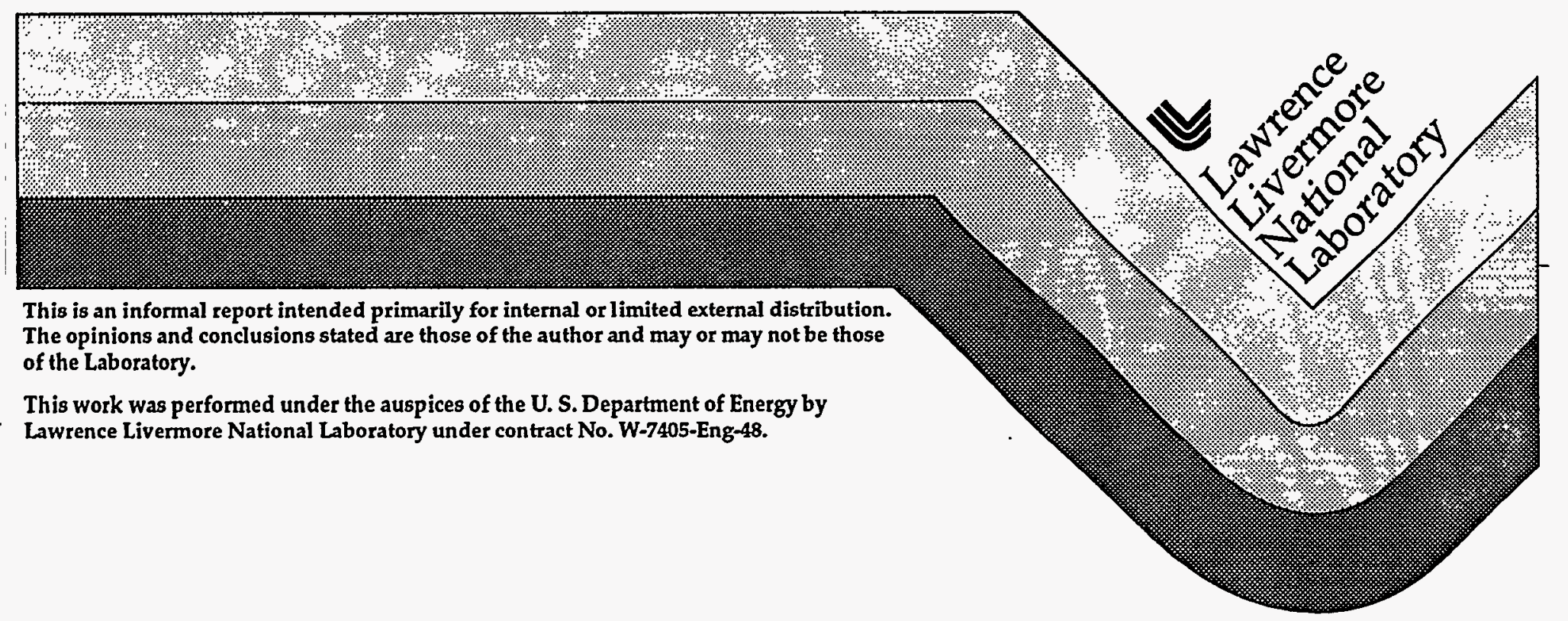




\section{DISCLAIMER}

This document was prepared as an account of work sponsored by an agency of the United States Government. Neither the United States Government nor the University of California nor any of their employees, makes any warranty, express or implied, or assumes any legal liability or responsibility for the accuracy, completeness, or usefulness of any information, apparatus, product, or process disclosed, or represents that its use would not infringe privately owned rights. Reference herein to any specific commercial product, process, or service by trade name, trademark, manu facturer, or otherwise, does not necessarily constitute or imply its endorsement, recommendation, or favoring by the United States Government or the University of California. The views and opinions of authors expressed herein do not necessarily state or reflect those of the United States Government or the University of California, and shall not be used for advertising or product endorsement purposes.

This report has been repoduced directly from best available copy

Available to DOE and DOE contractors from the Office of Scientific and Technical Information P. O. Box 62, Oak Ridge, TN 37831

Prices available from (615) 576-8401, FTS 626-8401

Available to the public from the National Technical Information Service

U. S. Department of Commerce

5285 Port Royal Rd.

Springfield, VA 22161 


\section{DISCLAIMER}

Portions of this document may be illegible in electronic image products. Images are produced from the best available original document. 


\section{Low Frequency Electromagnetic Signals from Underground Explosions-On Site Inspection Research Progress Report}

Jerry J Sweeney

July 21,1995

\section{INTRODUCTION}

We are investigating the characteristics of extremely low frequency (ELF) electromagnetic pulse (EMP) phenomena from underground nuclear and chemical explosions and from surface chemical explosions as they may be applied in an On-Site Inspection (OSI) context under a Comprehensive Test-Ban Treaty (CTBT). The principal application of these phenomena is for discrimination among underground chemical explosions, underground nuclear explosions, and earthquakes.

Underground chemical and nuclear explosions both generate low-frequency EMP signals (about $1 \mathrm{~Hz}$ ) that are observable within several kilometers of ground zero [Malik et al., 1985; Sweeney, 1989; Sweeney, 1995; Wouters, 1989; Zablocki, 1966]. These signals could be used during cooperative zerotime inspections to confirm the nature of large announced explosions for industrial purposes. To date, our knowledge of low-frequency EMP is empirical; the source of the low-frequency EMP is not well understood [Bevensee, 1990; Wouters, 1989]. During this fiscal year we have been gathering data from explosions of opportunity to see if ELF EMP signals are observable from large ripple-fired blasts and from smaller dedicated explosions such as those occurring at the NTS. In addition, we are continuing to review data from the Henderson Mine deployment that took place during FY94 and data from previous underground nuclear tests [Adushkin et al., 1995; Malik et al., 1985; Sweeney, 1989; Zablocki, 1966, including Hunter's Trophy and the NonProliferation experiment (NPE) [Sweeney, 1995].

In this report we summarize current results of the above activities. ELF EMP data from the Hunter's Trophy and NPE experiments have been re-calibrated after an error in the initial calibration of the instrumentation was discovered. These data and data from past underground nuclear tests [Sweeney, 1989] have been analyzed and we here make estimates of the properties of the EMP from underground nuclear and chemical explosions,

\footnotetext{
* e.g. explosions at mines or at the NTS for which LLNL is carrying out planned seismic monitoring experiments
} 
including detectability, dependence on yield, and dependence on distance from the source. Data from the Henderson Mine provide information about detection of EMP from typical moderate size underground chemical explosions in hard rock and problems related to detection of EMP in a mine environment located at high elevations. Data from the Carlin Mine site provide information about EMP from surface ripple-fired chemical explosions and detection in an open-pit mine environment. Data from the Kuchen experiment at NTS provide additional data about small underground chemical explosions in a setting similar to that for underground nuclear tests at the NTS.

\section{REVIEW OF ELF EMP DATA FROM UNDERGROUND NUCLEAR AND CHEMICAL EXPLOSIONS}

Atmospheric nuclear explosions create a significant EMP that can be detected world-wide [Balser and Wagner, 1963] and has been extensively studied because of its potential effect on communications, power systems, etc. Because of the skin effect due to earth conductivity, high frequency components of the EMP from underground explosions traveling through the ground are strongly attenuated. All reports of EMP from underground nuclear explosions at distances greater than a kilometer or more have been concerned with frequencies in the ELF/VLF range [Adushkin et al., 1995; Malik et al., 1985; Sweeney, 1989; Zablocki, 1966]. EMP from chemical explosions is a well-known phenomenon, but most studies have involved above ground explosions at frequencies in the $\mathrm{KHz}$ range or higher [Walker, 1970; Wouters, 1979]. The EMP from shallow borehole explosions, and the EMP associated with shock waves hitting a conductive interface (the seismoelectric effect) have been investigated for their exploration potential [Kepic et al., 1995; O'Keefe and Thiel, 1991]. Generally these shallow-burial explosions are detected within a few hundred meters distance at frequencies of $10 \mathrm{KHz}$ or higher.

Four different possible causes of the EMP from underground nuclear explosions have been proposed [Wouters, 1989]. These are (1) the so-called "magnetic bubble"expansion of the conductive cavity plasma "bubble" in the earth's magnetic field, (2) Faraday currents induced by ground motion beyond cavity formation, and (3-4) two processes driven by neutron-flux related Compton currents. Of these, the magnetic bubble appears to be the most likely source of ELF EMP. The magnetic bubble theory was analyzed by [Bevensee, 1990] and compared to the data of [Malik et al., 1985; Sweeney, 1989; Zablocki, 1966]; results were ambiguous. Distances, yields, and azmuthal coverage in the published data are not adequate for testing the theory. 
In an analysis of data from above ground chemical explosions, the EMP was attributed to two causes [Wouters, 1970] (1) asymmetric charge separation due to differential velocity effects (seen most strongly for non-spherical explosions), and (2) interference of the shock wave reflected from the ground with the gas/debris cloud. The source was characterized as a vertical electric dipole (no magnetic EMP was observed) associated with the expanding gas/debris region. Russian workers [Adushkin et al., 1995] have associated the EMP from such explosions with the "shorting" of the plasma cloud as it touches the ground. Based on results from the NPE underground explosion [Sweeney, 1995] (for which a magnetic EMP was seen), it seems likely that the source of the EMP from underground and above ground chemical explosions could be quite different.

To our knowledge, the EMP signals detected from the NPE [Sweeney, 1995] are the first reported from a deeply-buried chemical explosion. The NPE results suggest that the EMP from a chemical explosion is smaller than that from a nuclear explosion of similar yield, has a signal spectrum concentrated at lower frequencies, and occurs with significant delay after detonation (on the order of $10 \mathrm{~ms}$ ) relative to an underground nuclear explosion. At these ELF frequencies (approximately $1-40 \mathrm{~Hz}$ ) attenuation is much lower than at higher frequencies because of the relatively high conductivity $(0.01-0.002 \mathrm{~S} / \mathrm{m})$ of the rock and the associated skin effect. In fact, at these low frequencies EMP wavelength is on the order of tens or hundreds of kilometers (depending on earth conductivity) and the measurements are essentially being made of diffusive fields in the so-called "near field" or "quasi-static" field. In this regime, field strength is generally thought to decrease as the inverse cube of distance [Bevensee, 1990].

Electromagnetic signals have been reported from earthquakes [Fraser-Smith et al., 1990; Molchanov et al., 1992] in the ULF band (generally < $1 \mathrm{~Hz}$ ). Such signals have been reported for only a few earthquakes, larger than magnitude 6.0, and little is known about their source. Earthquakes and explosions at magnitude 6.0 and higher are not considered to be a difficult discrimination problem. EMP at ELF frequencies has not been reported from small earthquakes; thus EMP signals could conceivably be used as an additional discriminant between earthquakes and explosions.

In order to gain a better understanding of the ELF EMP from underground explosions, we reviewed data previously obtained from underground nuclear explosions [Sweeney, 1989] and compared it with the data obtained from the Hunter's Trophy underground nuclear test and from the NPE chemical explosion. The first step involved a correction to the absolute magnitudes of the signals recorded at Hunter's Trophy and the NPE, as reported by Sweeney (1995). The previously-published data were calibrated incorrectly. The correct scale values for the data are given in Table 1 . 
We used the data corrected in Table 1 and data from Sweeney (1989) to produce the plots shown in Fig. 1. Maximum magnitudes of the recorded electric or magnetic signals, vertical or horizontal component, were normalized to the yield of the explosion, in $\mathrm{Kt}$ (the source of the EMP has been assumed to vary linearly with yield [Wouters, 1989]; units for the vertical scale are not included for security classification reasons). The respective normalized yields are then plotted versus the slant distance of the sensors to the explosion in $\mathrm{km}$. Chemical explosion data is indicated by solid symbols in Fig. 1, nuclear explosion data by open symbols. The cluster of nuclear explosion data at distances of $5-10 \mathrm{~km}$ suggests that the source of the EMP is quite variable. For example, at a distance of about 7$8 \mathrm{~km}$, both electric and magnetic sensors show a variability of about a factor of 10 in scaled signal strength; some data indicate invariance of scaled signal strength at measurement distances of $5-10 \mathrm{~km}$. This may be due to factors such as the canister design, buffer materials around the device, location and orientation of cables and surface structures, or azmuthal signal variation. There are no data at distances of 5-10 $\mathrm{km}$ from underground chemical explosions, so the distance dependence cannot be assessed. The data suggest that, for underground nuclear tests, the scaled electric field decreases as the inverse square of distance and that the scaled magnetic field decreases as the inverse cube of distance; the sparse data does not rule out the possibility of an inverse cube dependence on distance for the electric field. If one assumes that chemical explosions have less variability in the EMP source term than is shown by nuclear explosions, then the data from the NPE suggest that the magnitude of the magnetic EMP from a chemical explosion is about an order of magnitude smaller than for a similar yield nuclear explosion.

Sparseness of the data in Fig. 1 and their uneven distribution rule out definitive conclusions; because some estimates of detection capabilities are needed, we have gone ahead with some assumptions. Data from Fig. 1 were used to make estimates of the maximum distance for detection (assuming that the signal must be at least 2 times larger than average background noise: $20 \mathrm{pT}$ for magnetic, 2 microvolts $/ \mathrm{m}$ for horizontal electric) at different yields for chemical and nuclear explosions. We assumed that the source of the electric (horizontal component) and magnetic fields varied linearly with yield and chose scale factors to fit the data of Fig. 1. Therefore, the electric field varies as $\mathrm{E}=\mathrm{K}_{\mathrm{EW}} / \mathrm{r}^{2}$, and the magnetic field varies as $B=K_{B} W / r^{3} ; E$ and $B$ are electric and magnetic field strength respectively, $\mathrm{K}_{E}$ and $\mathrm{K}_{\mathrm{B}}$ are scale factors, $W$ is yield in kilotons, and $r$ is slant range in meters. For $\mathrm{K}_{\mathrm{E}}$ we estimated (visual fit to data) a value of $2.4 \cdot 10^{6} \mu \mathrm{v}-\mathrm{m} / \mathrm{Kt}$; most data will lie between $\mathrm{K}_{\mathrm{E}}$ values of $4.8 \cdot 10^{5}$ to $1.2 \cdot 10^{7} \mu \mathrm{v}-\mathrm{m} / \mathrm{Kt}$. For $\mathrm{K}_{\mathrm{B}}$ we estimated a value of $1.6 \cdot 10^{11} \mathrm{pT}-\mathrm{m}^{3} / \mathrm{Kt}$ with a range of $3.2 \cdot 10^{10}$ to $8.1 \cdot 10^{11} \mathrm{pT}-\mathrm{m}^{3} / \mathrm{Kt}$. The maximum slant range distances in Fig. 2 were calculated using the above expressions and source term 
extrema. As mentioned above, the data suggest that chemical explosion EMP may be as much as an order of magnitude smaller than an equivalent yield nuclear explosion EMP. The shape of the EMP would provide an additional discriminant (see Sweeney, 1995). Because there is no appreciable delay (detectable with a $200 \mathrm{~Hz}$ sampling rate) of the initiation of the EMP from a nuclear explosion, the EMP signal can be used to identify the origin time of the event. The estimates of Fig. 2 are consistent with data from the $300 \mathrm{lb}$. calibration test carried out before the NPE. No signal was detected at a distance of $500 \mathrm{~m}$. The table suggests about $50-140 \mathrm{~m}$ for the maximum detection distance.

\section{THE HENDERSON MINE DEPLOYMENT}

Henderson mine is a block-caving mine located approximately $100 \mathrm{~km}$ west of Denver, Colorado. Ore is produced by undermining sections of the orebody and allowing the ore to collapse in on itself, which produces a collapse process not unlike that which occurs during chimney formation after a nuclear explosion. The mine is located about 1500 $m$ underground in a mountainous area that reaches elevations of more than $3600 \mathrm{~m}(12,000$ $\mathrm{ft}$ ). The region is covered with a heavy blanket of snow for about 6 months of the year. Two ELF electromagnetic (EM) stations were established during the summer, 1994, deployment, with locations shown in Fig. 3. Three orthogonal (Z, N, E) magnetometers (the same system used at the NPE and Hunter's Trophy) were installed at the QRY site, with three orthogonal magnetometers and two horizontal orthogonal $(N, E)$ telluric lines installed at the TAL site. See Fig. 4 for a general explanation of a typical sensor and data acquisition system installation. Sampling rates at each site were set at $200 \mathrm{~Hz}$. Both ELF EM sites were co-located with a seismometer station so that we could identify the arrival of ground motion at the EM sensors.

The QRY site is located near mechanical equipment associated with surface mine operations. Operation of large motors and local vehicle traffic produced very high levels of $60 \mathrm{~Hz}$ cultural noise. This high noise level may be a reason why the arrival at the QRY site of surface wave ground motion from the explosion (which is usually recorded even though there is no zero-time EMP) was not registered for explosions as large as $2500 \mathrm{lb}$. Data typical of this site is shown in Fig. 5 for a $2500 \mathrm{lb}$ explosion on July 19, 1994. The arrival of ground motion at the site is obvious from the lower three seismometer traces, but there is no indication of any ground motion being picked up by the magnetometers. Noise levels at the magnetometers are quite high, with significant components of noise at $60 \mathrm{~Hz}$ and 30.5 $\mathrm{Hz}$ as well as at frequencies below $10 \mathrm{~Hz}$. Noise on the $\mathrm{E}$ and $\mathrm{W}$ sensors is about 4-5 times higher than typical background levels, while the vertical component is about 40 times 
higher. Presumably this noise comes from the nearby mechanical equipment associated with mine operations as well as some nearby vehicle traffic. Ground motion signals from the $300 \mathrm{lb}$ calibration shot at NTS, from sensors located at $500 \mathrm{~m}$ slant range, were about the same level as the noise on the horizontal magnetometers at the QRY site. The QRY site is located several kilometers from the explosive source in this case, so it is not surprising that the ground motion was not detected, given the noise levels.

The TAL site, at the opposite side of the mountain from the QRY site, also experienced high levels of $60 \mathrm{~Hz}$ noise, but these were mitigated somewhat by the use of $60 \mathrm{~Hz}$ notch filters on the $\mathrm{N}$ and $\mathrm{Z}$ magnetometers and on the telluric lines (we didn't have enough filters available during installation for the sensors at the QRY site). Signals recorded during a $1500 \mathrm{lb}$ explosion on September 15, 1995 are shown in Fig. 6. In this plot, the vertical seismometer traces from both the QRY and TAL site are shown. The eastdirected magnetometer did not have a $60 \mathrm{~Hz}$ notch filter, data from this sensor is not shown because of very high noise levels. The north telluric line was inoperative on this date, so that data is also not shown. The onset of ground motion is clearly seen at both sites; the accelerometer at the TAL station has a higher frequency response than the seismometer at the QRY station. Noise levels at each of the EM sensors are generally quite high and no . evidence of ground motion is seen. The low frequency spikes seen on the vertical magnetometer at $\mathrm{QRY}$ and on the $\mathrm{N}$ and $\mathrm{Z}$ magnetometers at TAL occur simultaneously at both stations. These spikes are probably from local lightning strikes-thunderstorms are an almost daily afternoon occurrence at these elevations during summer. These data are typical of that obtained from the QRY and TAL sites. Of the 16 explosion events identified so far in the data at Henderson mine, with blasts ranging from 500 to $2500 \mathrm{lbs}$ of explosive, we have seen no evidence of an EMP or any response of the EM sensors to ground motion due to the explosions.

Both ELF EM sites at the Henderson mine were located about as close as we could get to the blasting and still remain at the ground surface. In this case, we did not detect any EMP signals from explosions in the mine; which occurred at least $2 \mathrm{~km}$ away from the sensors. This is consistent with Fig. 2, which suggests that a chemical explosion would have to be nearly $10 \mathrm{Kt}$ in size to be detected at this range, although a 1-2 Kt explosion would be on the margin of detection.

This deployment gave us experience in obtaining EM data in a mountainous mining region under typical conditions of mine operations. The high levels of noise encountered at this site prompted us to obtain improved filters for $60 \mathrm{~Hz}$ rejection. 


\section{THE CARLIN MINE DEPLOYMENT}

The Carlin Gold Mine, operated by the Newmont Gold Company, is located near Elko, Nevada at an elevation of about $1500 \mathrm{~m}(5000 \mathrm{ft})$. The mine consists of several large open pits in which large amounts of rock are blasted free and removed for processing at the central separation facility. The site works multiple shifts 5 days per week. Blasting primarily consists of large ripple-fired explosions to break up benches typically $30 \mathrm{~m}$ high and $300 \mathrm{~m}$ by $100 \mathrm{~m}$ in area or larger. A typical explosion may involve 800 boreholes, each containing $200 \mathrm{lb}$ of explosive, with banks of boreholes fired with delays of 20-100 ms.

We obtained a number of $40 \mathrm{~Hz}$ low-pass active elliptical filters (5-pole) to ensure maximum rejection of $60 \mathrm{~Hz}$ cultural noise for this deployment. These filters have a very steep drop-off after the corner frequency and performed well in field trials. Most of the low frequency EMP signals that have been detected to date from chemical and nuclear underground explosions have been in the $1-10 \mathrm{~Hz}$ range, so we felt that the system performance would not be adversely affected by cutting off all frequencies above $40 \mathrm{~Hz}$.

We installed three magnetometers $(E, N, Z$ ), a vertical electric antenna (of the same ball-over-plate capacitor design used previously [Sweeney, 1989], and an east-west $100 \mathrm{~m}$ telluric line on a $15 \mathrm{~m}$-wide bench on the north side near the top of the main pit in the mine referred to as "Gold Quarry". The site is $500-750 \mathrm{~m}$ line-of-site from the Gold Quarry blasting area and several $\mathrm{km}$ away from blasting areas in other parts of the mine.

Data from a ripple-fired blast in the nearby Gold Quarry on April 27, 1995 is shown in Fig. 7. Data from the seismometer at this site was taken with a separate acquisition system and is not yet available for this site. The east-west telluric line was inoperative at the time data was acquired (a rock fall from a previous blast at the site may have affected it). The three magnetometers clearly show the arrival of ground motion from the blast. Note that noise levels are much lower in this figure compared to previous data due to the use of the active low-pass filters. There is a strong spike seen at $235 \mathrm{~s}$ into the record on the $\mathrm{E}$ and $\mathrm{Z}$ magnetometers. This is probably not related to the blast, because it occurs too long before the arrival of ground motion (about $2 \mathrm{~s}$ in this case). The smaller EM spike that occurs about $236.5 \mathrm{~s}$ into the record may possibly be related to ignition of the blast. This is the only such signal that could possibly be an EMP from the chemical explosion that we have seen at this site. More typical data is that shown in Fig. 8. Again, the telluric line was inoperative. There is no indication of an EMP related to the explosion, although the ground motion arrival at the sensors (especially the magnetometers) is clearly identified. 
Our preliminary conclusion from the data at this mine is that ripple fired blasting does not create an enhanced EMP signal over that expected from a single borehole alone. The EM sensor station at Carlin was 500-750 $\mathrm{m}$ from the blast location. Using Fig. 2, the minimum single chemical explosion detectable is between 0.1 and $1 \mathrm{Kt}(200,000$ to $2,000,000 \mathrm{lb}$.). This is greater than the combined explosive used for the entire blast, which may be as much as 160,000 to $200,000 \mathrm{lb}$. However, this estimate is based on diffusion of the EMP through the ground, whereas at the Carlin Mine the surface blasts would have a component of the field diffusing or propagating through the atmosphere. These results

suggest that low-frequency EMP may not be present for large ripple-fired blasts. At leașt it is no greater than that expected from a single blast of equivalent explosive weight. In this case, the only way to be any closer to the blast would have been to deploy in the pit, within the "throw" zone (where debris is thrown from the blast)—clearly a location very intrusive to mine operations.

\section{THE KUCHEN EXPERIMENT AT THE NEVADA TEST SITE}

Kuchen is a Nuclear Test Program readiness experiment in which a $100 \mathrm{lb}$ chemical explosion is detonated at a depth of $93 \mathrm{~m}$ (305 ft) in a borehole at Yucca Flat (Area 9). The test plan is to carry out three explosions: first the explosive is emplaced at the bottom of the borehole and grouted in rock, with a plug seal above it; secondly, a similar explosive is placed in an open cavity above the location of the first explosion; in the third case, a $100 \mathrm{lb}$. explosion is detonated in the grouted-in cavity from the second explosion. The purpose of the experiment is to acquire close-in and regional ground motion data for validation of codes describing source effects and ground motion near a tamped and untamped explosion.

Our interest in the ELF EMP effects of this explosion arises because of the second, decoupled explosion. If the source of the EMP from chemical explosions is related to plasma.size, explosion in a cavity will create a larger.plasma than a similar tamped explosion and we would expect a larger EMP. We can site the sensors no closer than the burial depth of the explosive $(93 \mathrm{~m})$. Fig. 2 suggests that the maximum detection limitfor a $100 \mathrm{lb}$ chemical explosion is about $30 \mathrm{~m}$, so we would not expect to see an EMP from the tamped explosion. However, we have no data to know what to expect for the decoupled explosion and there may be a possibility that something will be seen.

The ELF EM station installed for the Kuchen test was located approximately $20 \mathrm{~m}$ from surface ground zero (SGZ), a slant range of about $95 \mathrm{~m}$ from the explosive. Because of space limitations, no telluric (horizontal electric field) lines were emplaced. Three (E, N, Z) magnetometers and a vertical electric antenna were installed. A new type of optical pre- 
amplifier (to obtain better electrical isolation) was used with the vertical electric sensor, otherwise the system is identical to that used previously. The initial tamped explosion was detonated on June 22, 1995.

Data obtained from the ELF station on June 22 is shown in Fig. 9. Noise levels are quite low for the sensors because generators, air conditioners, etc. were shut off in the area prior to the detonation in order to reduce noise levels for the seismic array. In addition, winds at Yucca Flat are often calm during the early morning hours during summer. The ground motion from the explosion is clearly seen at the ELF sensors, most prominently at the magnetometers. The horizontal magnetometers show an initial pulse, a short gap, and a longer train of oscillations. The explosion was detonated at $72 \mathrm{msec}$ past the hour of 6:00 a.m. local time (0600:00:072 PDT_B in Fig. 9). The initial pulse in Fig. 9 occurs $62 \mathrm{~ms}$ after the hour (at $A$ in Fig. 9). The secondary pulse, marked by $G$ in Fig. 9, (which arrives the same time as ground motion begins at a nearby seismometer) occurs at about $147 \mathrm{~ms}$ past the hour. The $85 \mathrm{~ms}$ delay between pulses $A$ and $G$ matches the delay between the fiducial pulse (detonation time) and the first ground motion at the nearby seismometer.

The apparent early arrival of the initial pulse is probably due to a timing error in the Reftek data acquisition system at the ELF site. Examination of the data system messages reveals that the system clock at the Reftek had not locked in to the satellite reference for at least eight hours prior to the detonation. Prior to the last lock-in, the system clock had been off by 0.5 to $1 \mathrm{~ms}$ per hour. Thus the $10 \mathrm{~ms}$ discrepancy in the initial EMP timing is most probably due to a system clock error.

The initial, apparent, EMP is a very large signal. The $\mathrm{N}$ and $\mathrm{Z}$ components of the signal are nearly equal to the ground motion signal - about 200 pT. The signal-to-noise ratio for this signal is at least 10 . It seems to be much too large to be related to the downhole chemical explosion detected at the distance of the ELF site. One possible explanation is that the EMP comes from the detonator circuit at the top of the borehole. A bank of capacitors is charged and used to create a pulse a few hundred microseconds in width to detonate the explosive. It is possible that this detonator circuit is responsible for the large EMP recorded. This hypothesis will be tested before the decoupled experiment in August by discharging the detonator circuit into a dummy load while the ELF sensors are recording. If the detonator circuit is responsible for the EMP, we may be able to shield the system to prevent propagation of the pulse; otherwise we can never hope to see an EMP from the explosion itself. 


\section{SUMMARY}

Underground chemical and nuclear explosions both produce an electromagnetic pulse. Amplitudes of the magnetic field seem to decrease as the cube of distance from the source, electric fields may decrease as the square of the distance. If the EMP is produced by the expanding plasma for both nuclear and chemical explosions, then one would expect the signal magnitude to scale linearly with yield (the plasma volume varies as the cube of cavity radius; cavity radius varies as the cube root of the yield). Data currently available from nuclear tests show a great deal of scatter, making it difficult to confirm the linear relation with yield. The source term for the EMP from underground nuclear explosions is probably highly dependent on the experiment design, containment geometry, and the azmuthal location of the sensors relative to ground zero. Variations in EMP strength of as much as an order of magnitude have been observed for explosions of similar yield. A linear relation between magnitude of EMP and explosive weight for chemical explosions has been reported in the literature, but this is mainly for explosions of less than $100 \mathrm{lb}$.

Data analyzed to date from underground chemical and nuclear explosions suggest that the magnetic field pulse from chemical explosions is about an order of magnitude smaller, has a longer duration, contains lower frequency components in $1-20 \mathrm{~Hz}$ range, and may be delayed by several milliseconds from the initial detonation. The electric field pulse shows the same character as the magnetic field, but in this case amplitudes for chemical explosions seem to be similar to those of nuclear explosions of similar yield (the data for this is quite sparse).

Detection of EMP from chemical explosions less than $20,000 \mathrm{lb}$ requires that the sensors be placed within $200 \mathrm{~m}$ of the explosive. This is probably too intrusive to be allowed under-normal mining operations. Larger single explosions are quite rare, so opportunities to obtain further data from chemical explosions will be sparse. Our experience at the Carlin Mine suggests that the EMP from ripple fired explosions is probably less than that of a single explosion equivalent to the total charge.expended in the ripple furing.

\section{REFERENCES}

Adushkin, V. V., V. A. Dubinya, V. A. Karaseva, S. P. Soloviev, and V. V. Surkov, Generation of low-frequency electric and magnetic fields during large-scale chemical and nuclear explosions, Academy of Sciences, Russian Federation, Institute for Dynamics of the Geosphere, Livermore, CA, 1995. 
Balser, M., and C. A. Wagner, Effect of a high-altitude nuclear detonation on the earthionosphere cavity, Jour. Geophys. Res., 68, 4115-4118, 1963.

Bevensee, R. M., Examination of Yield Determination by the Magnetic Bubble Effect, Lawrence Livermore National Laboratory Report, Livermore, Ca, 1990.

Fraser-Smith, A. C., A. Bernardi, P. R. McGill, M. E. Ladd, R. A. Helliwell, and J. O. G. Villard, Low-frequency magnetic field measurements near the epicenter of the MS-7.1 Loma-Prieta earthquake, Geophysical Research Letters, 17(9), 1465-1468, 1990.

Kepic, A. W., M. Maxwell, and R. D. Russell, Field trials of a seismoelectric method for detecting massive sulfides, Geophysics, 60(2), 365-373, 1995.

Malik, J., R. Fitzhugh, and F. Hormuth, Electromagnetic Signals from Underground Nuclear Explosions, Los Alamos National Laboratory Report, Los Alamos, NM, 1985.

Molchanov, O. A., Y. A. Kopytenko, P. M. Voronov, E. A. Kopytenko, T. G. Matiashvili, A. C. Fraser-Smith, and A. Bernardi, Results of ULF magnetic field measurements near the epicenters of the Spitak and Loma-Prieta earthquakes - comparative analysis, Geophysical Research Letters, 19, 1495-1498, 1992.

O'Keefe, S. G., and D. V. Thiel, Electromagnetic emissions during rock blasting, Geophysical Research Letters, 18(5), 889-892, 1991.

Sweeney, J. J., An Investigation of the Usefulness of Extremely Low-Frequency Electromagnetic Measurements for Treaty Verification,, Lawrence Livermore National Laboratory Report, Livermore, Ca, 1989.

Sweeney, J. J., Low-frequency electromagnetic measurements at the NPE and Hunter's Trophy: a comparison, in Proceedings of the Symposium on the Non-Proliferation Experiment, edited by M. D. Denny, pp. 8.21-8.33, Lawrence Livermore National Laboratory, Livermore, Ca, 1995.

Walker, C. W., Observation of the Electromagnetic Signals from a High Explosive Detonation, Lawrence Livermore National Laboratory Report, Livermore, Ca, 1970. 
Wouters, L. F., Implications of EMP from High Explosive Detonation, Lawrence Livermore National Laboratory Report, Livermore, Ca, 1970.

Wouters, L. F., H.E. EMP - the "HASH", Lawrence Livermore National Laboratory, Livermore, $\mathrm{Ca}, 1979$.

Wouters, L. F., The Underground Electromagnetic Pulse: Four Representative Models, Lawrence Livermore National Laboratory Report, Livermore, Ca, 1989.

Zablocki, C. J., Electrical transients observed during underground nuclear explosions, Journal of Geophysical Research, 71, 3523-3542, 1966. 
Table 1. Correction values for data reported in Sweeney (1995). To get the proper scale values for the indicated data, multiply the scale used in the figure by the amount indicated.

Hunter's Trophy [Figs, 2 and 3, D. 8-25, 26 of Sweeney (1995)]

$\begin{array}{cll}\text { Station } & \text { Component } & \text { Multiplier } \\ \text { H5 } & \mathrm{Bz} & 32 \mathrm{X} \\ \mathrm{H} 5 & \mathrm{Br}, \mathrm{Bt} & 8 \mathrm{X} \\ \mathrm{H} 5 & \mathrm{Er}, \mathrm{Et} & 8 \mathrm{X} \\ & & \\ \mathrm{E} 6 & \mathrm{Bz}, \mathrm{Br}, \mathrm{Bt} & 8 \mathrm{X}\end{array}$

300 pound calibration test [Fig, 5; D. 8-29 of Sweeney (1995)]

Station Component Multiplier

E6 $\mathrm{Bz}, \mathrm{Br}, \mathrm{Bt} \quad 8 \mathrm{X}$

NPE [Figs, 6 and 7, p. 5-30, 31 of Sweeney (1.995)]

$\begin{array}{cll}\text { Station } & \text { Component } & \text { Multiplier } \\ \text { Q4: } & \mathrm{Bz}, \mathrm{Br}, \mathrm{Bt} & 8 \mathrm{X} \\ \mathrm{Q} 4 & \mathrm{Er}, \mathrm{Et} & 8 \mathrm{X} \\ \text {. } & & \\ \mathrm{E} 6 & \mathrm{Bz}, \mathrm{Br}, \mathrm{Bt} & 8 \mathrm{X}\end{array}$




\section{Underground Test Data}
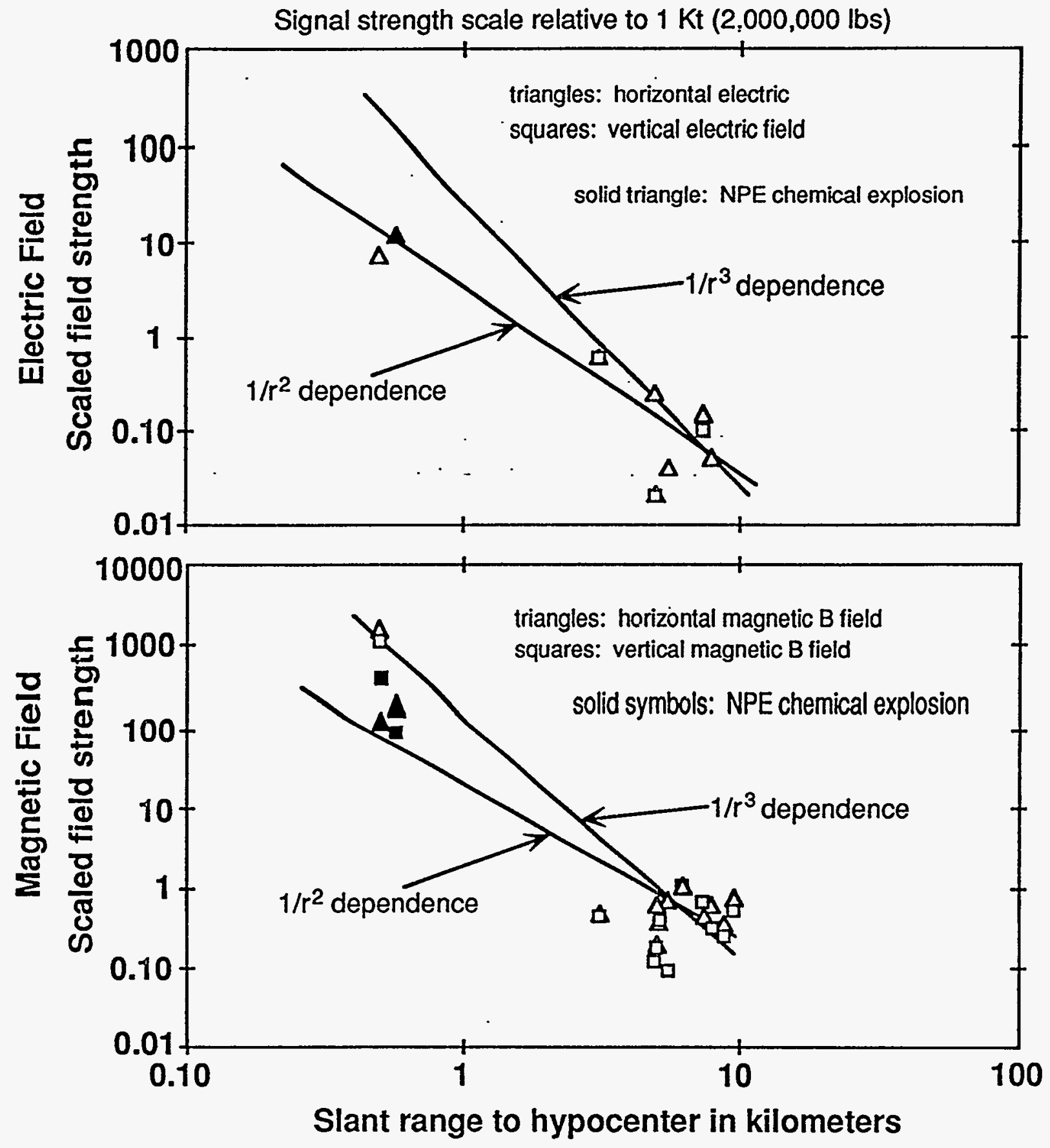

Figure 1. Plots of scaled field strength versus distance for EMP signals recorded at the NTS from underground nuclear and chemical explosions. Field strength is normalized relative to yield in $\mathrm{Kt}$. 

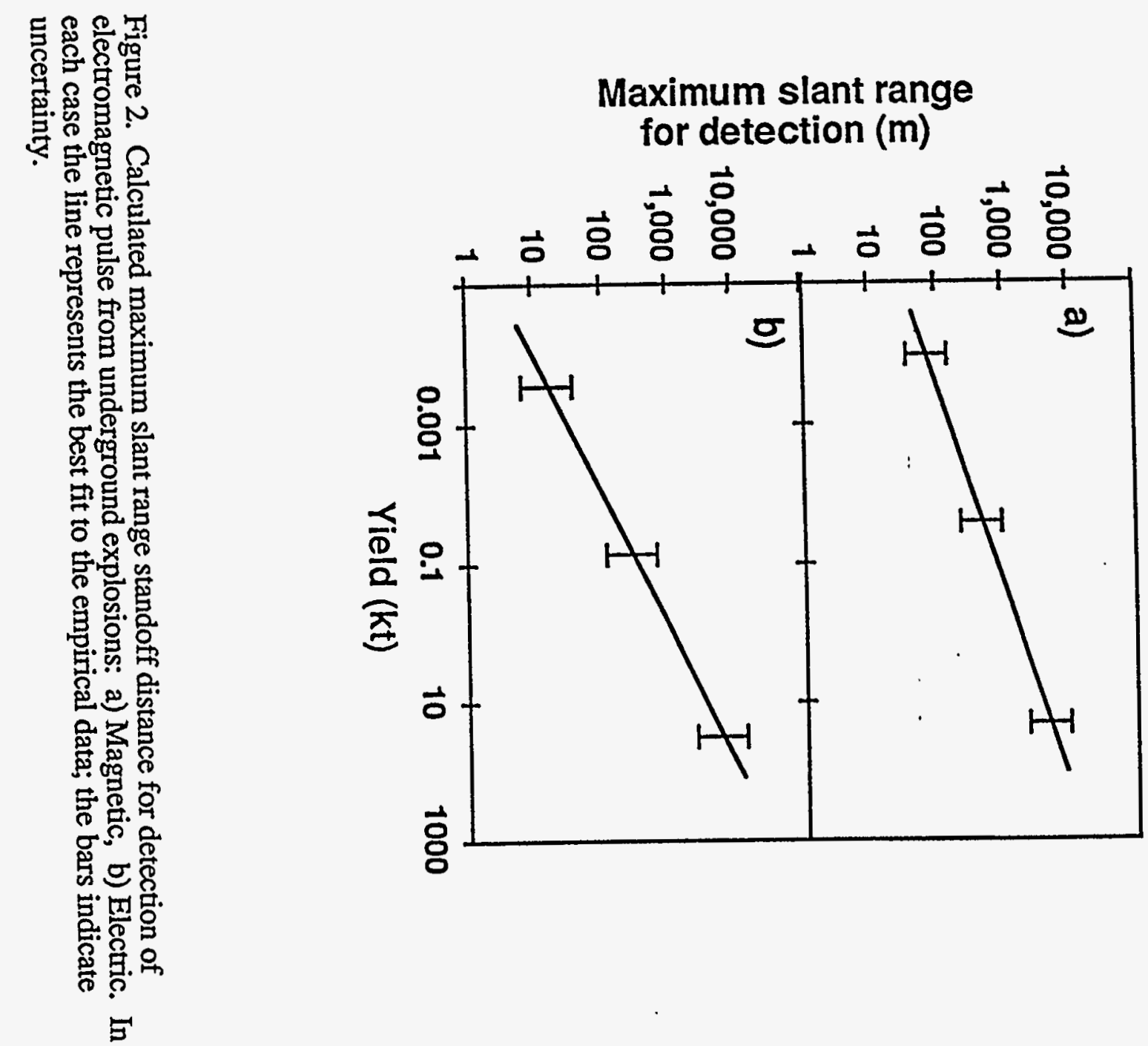


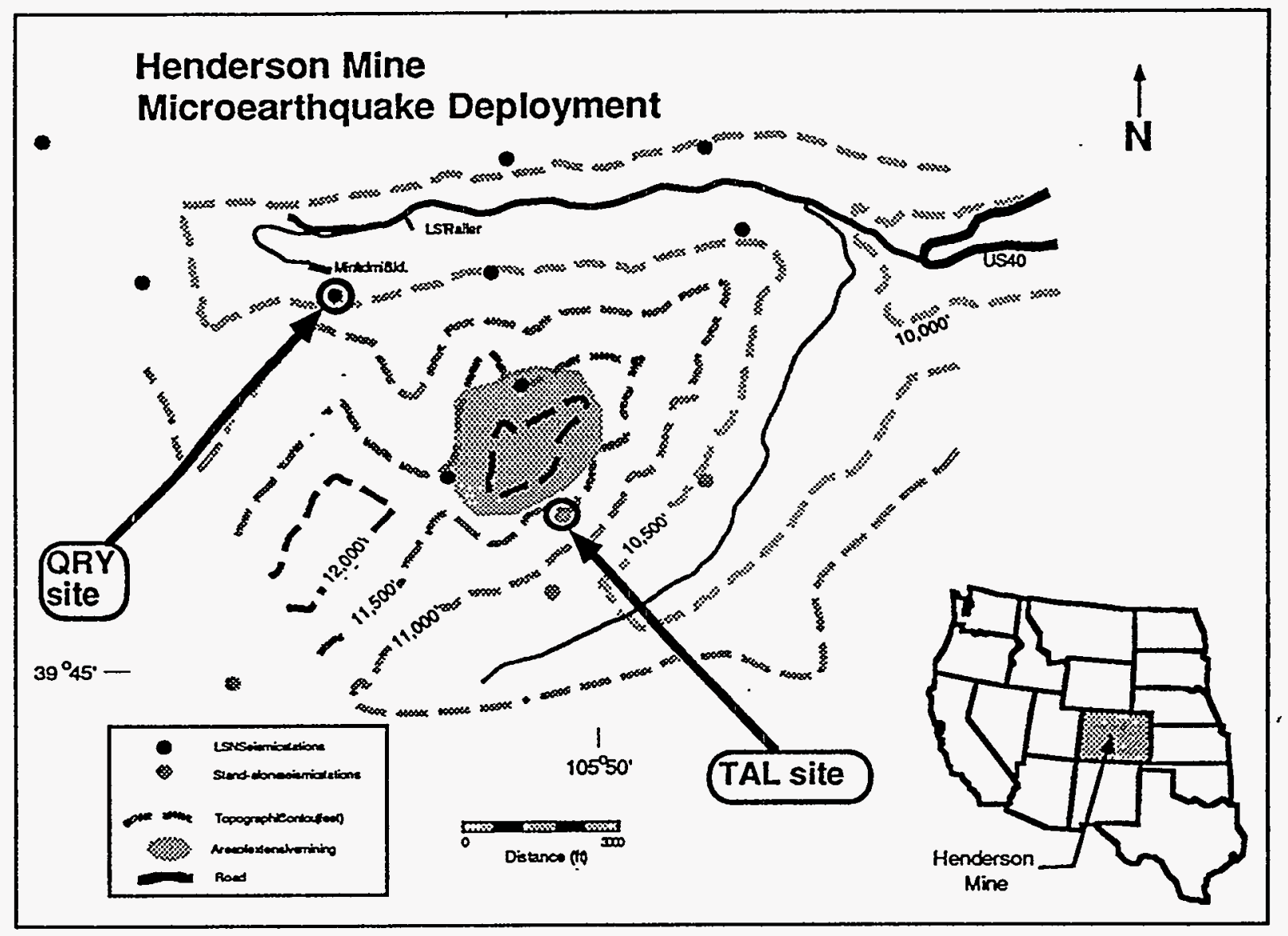

Figure 3. Location of the two ELF EM stations used at the Henderson Mine, Colorado. The mine administration building is at $10,500 \mathrm{ft}$ elevation. Mine workings are several thousand feet underground. 


\section{Magnetic field measurement}

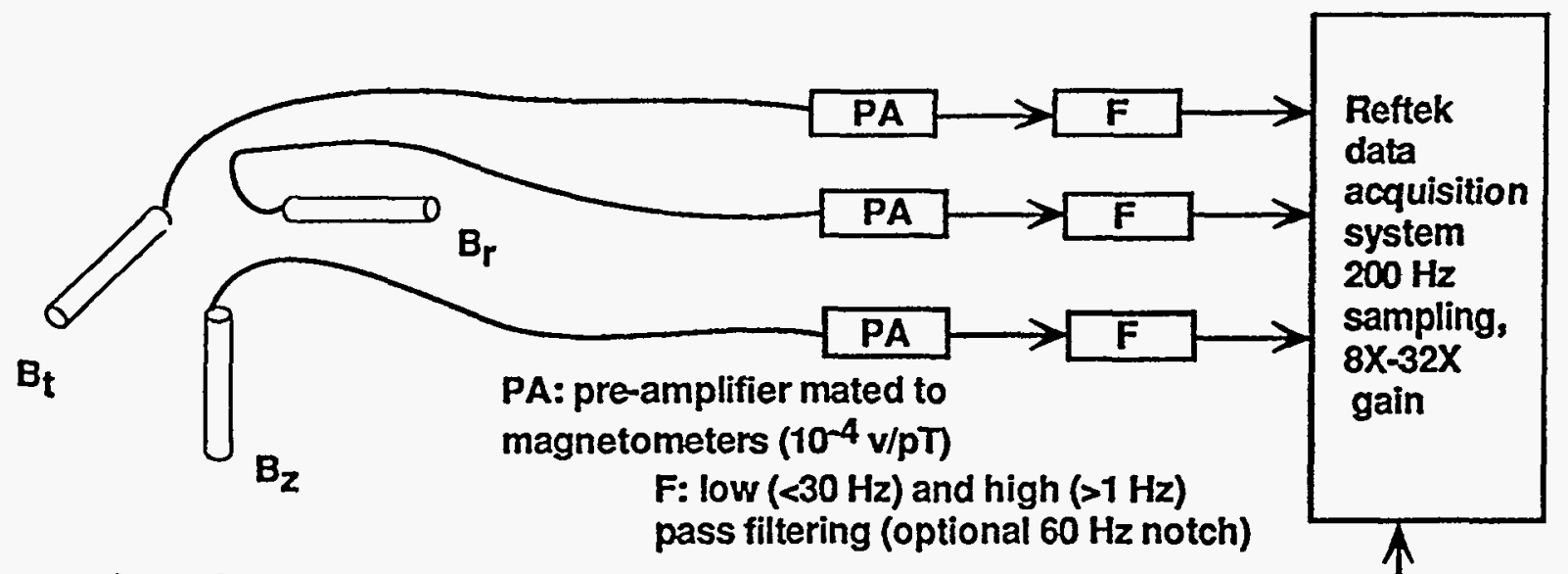

magnetometers are high $\mu$-metal core coils, low noise, flat from $1-100 \mathrm{~Hz}$

\section{Electric field measurement}

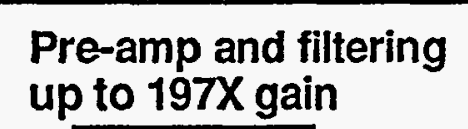

Figure 4. Field set-up for measuring low frequency EM fields. Magnetic sensors are buried a few inches into the earth (when possible) to minimize wind noise. The vertical electric antenna is essentially a ball-over-plate capacitor. It needs approximately a $0.75 \mathrm{~m}$ deep hole in the ground to emplace the pipe to minimize wind vibration. 


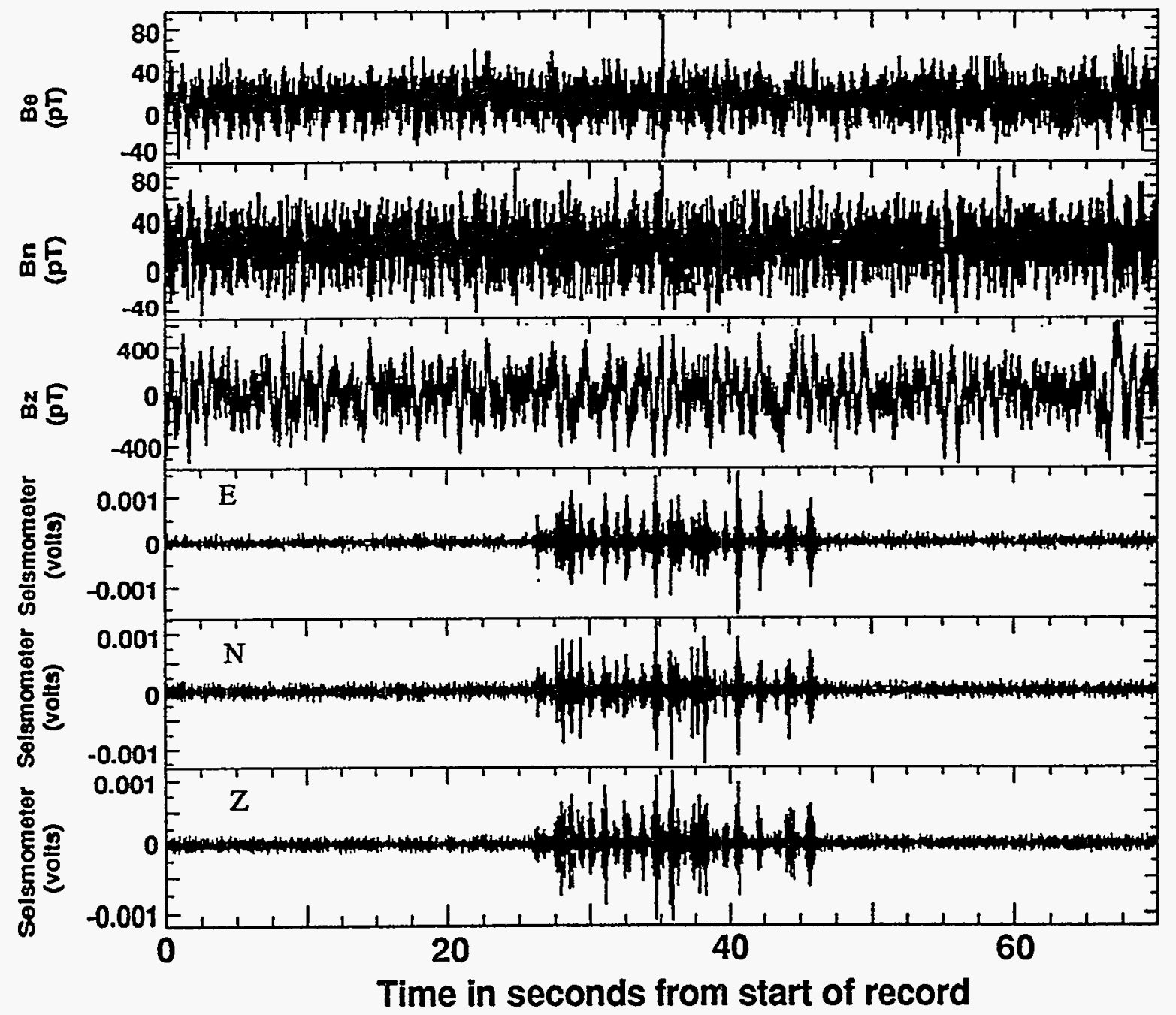

Figure 5. $2500 \mathrm{lb}$ explosion recorded at QRY site (see Fig. 3) at Henderson Mine, Colorado, on July 19, 1994. The top three traces are east, north, and vertical magnetic fields, respectively, The lower three traces are the east, north, and vertical seismometer records (raw voltage output). Arrival of ground motion at the site is obvious on the seismometers; only noise is recorded by the magnetometers. 


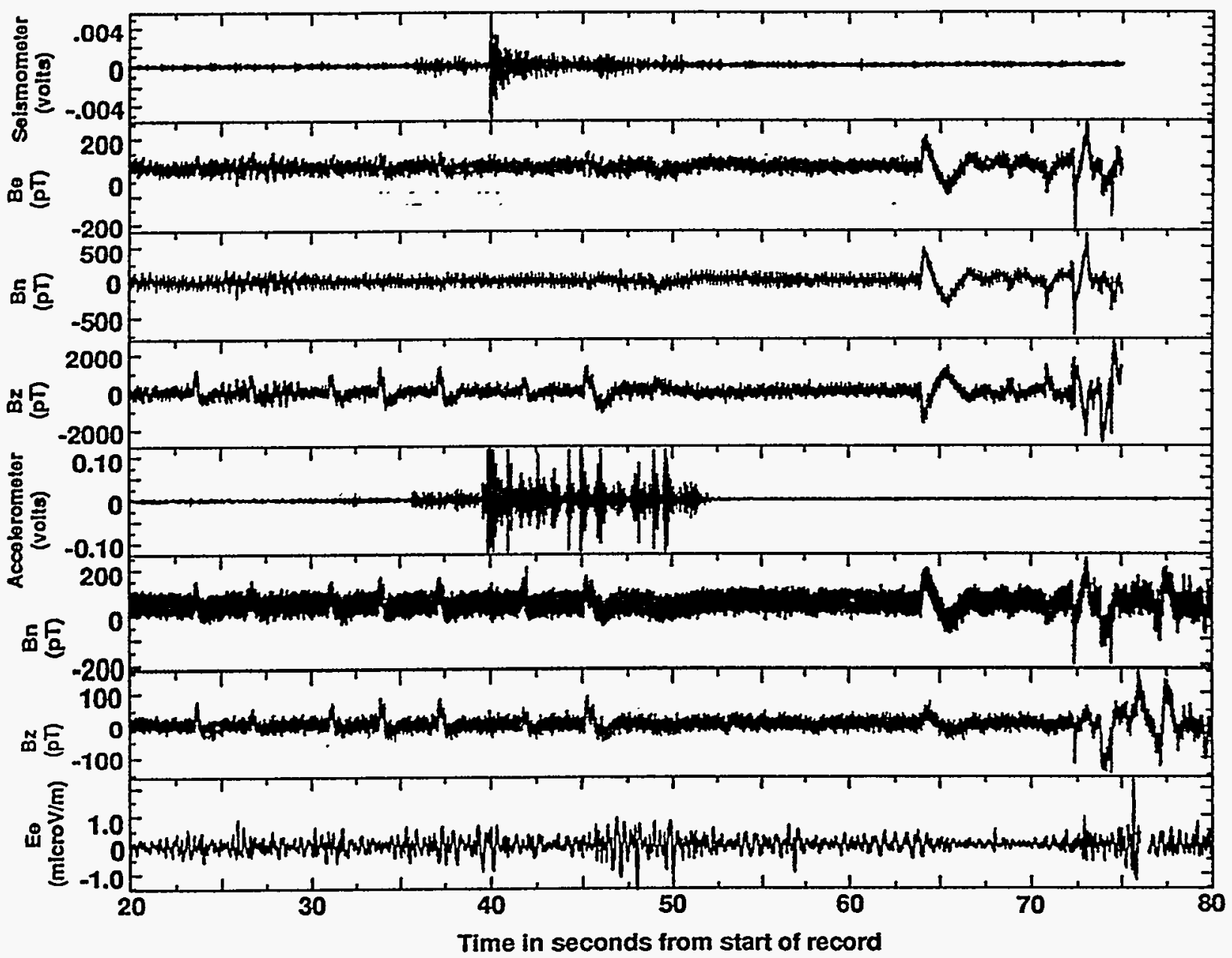

Figure 6. Data from a single explosion at Henderson Mine, Colorado, on September 15, 1994. The top four traces are from a seismometer (top - raw voltage output) and three magnetometers (lower three) ai the QRY site (see Fig. 3). The lower four traces are from an accelerometer (top raw voltage output), two magnetometers (middle two) and an east-directed telluric line (bottom) at the TAL site. Strong pulses seen at random intervals on the magnetometer traces are probably from nearby lightning. 


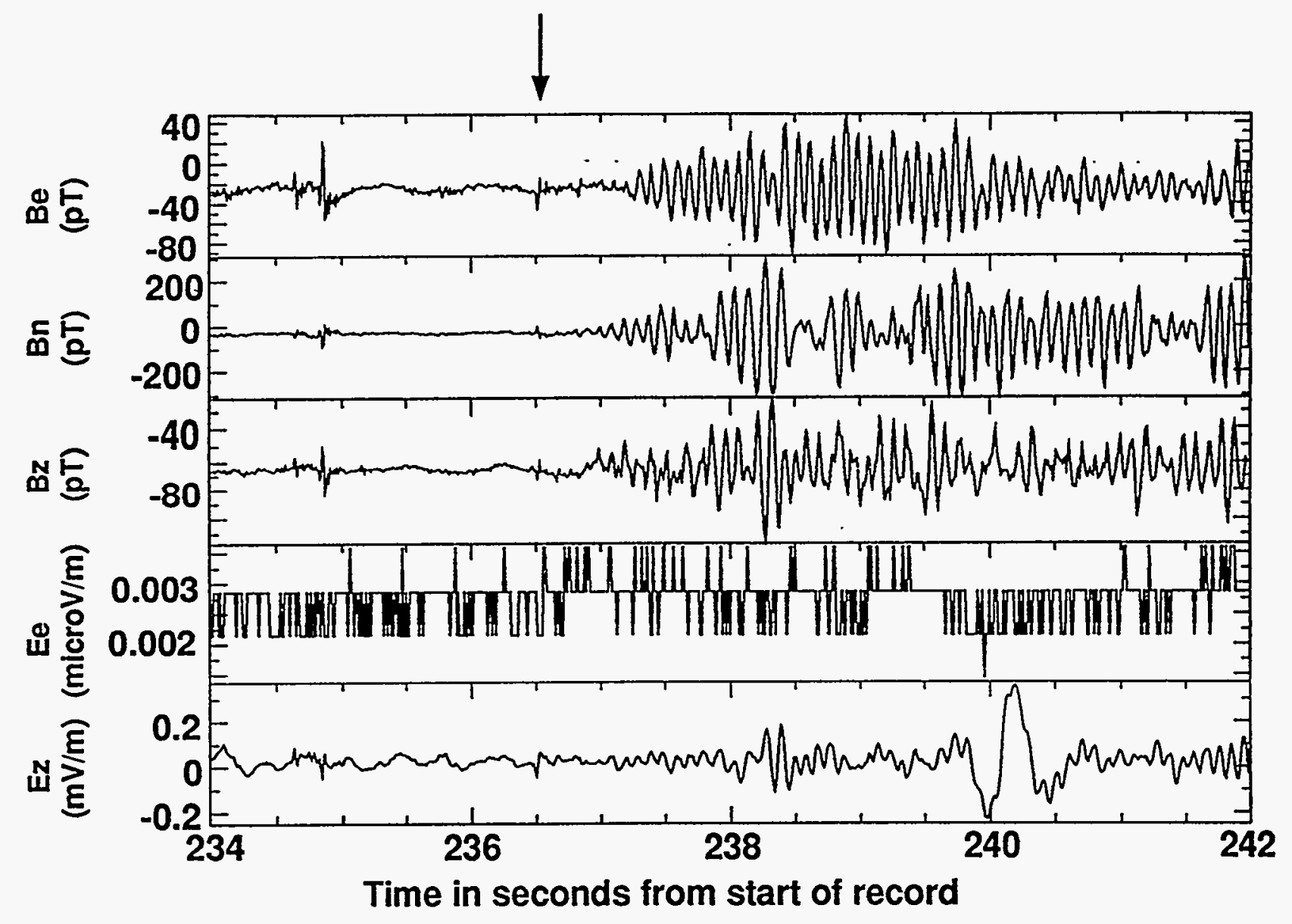

Figure 7. Electromagnetic signals recored during a ripple-fired explosion at Gold Quarry, Carlin Nevada, on April 27, 1995. The top three traces are magnetic field; the lower two traces are electric field. The east electric field sensor (Ee) was inoperative at the time of the explosion. The small amplitude pulse marked by the arrow might be associated with initiation of the explosion. 


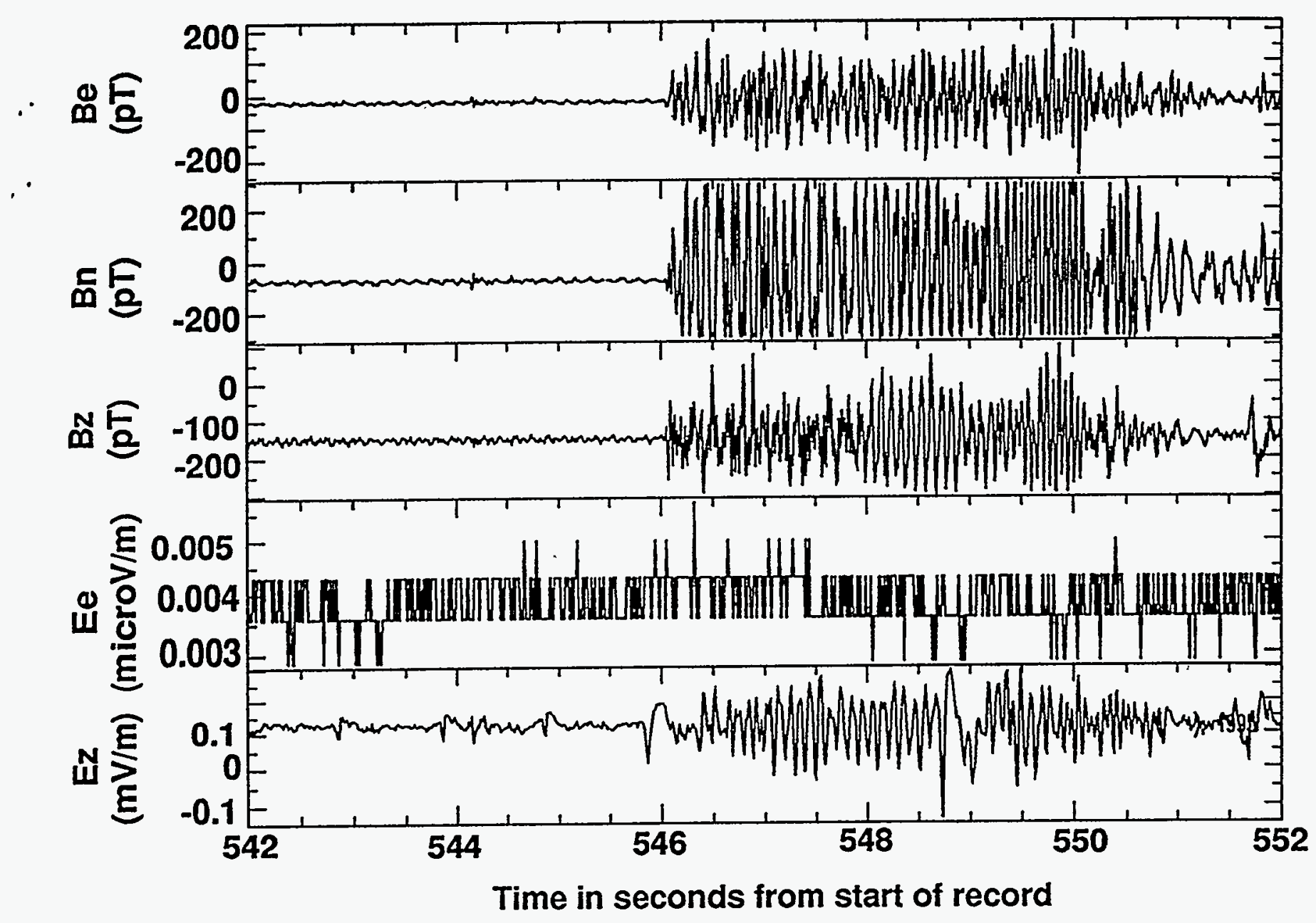

Figure 8. Electromagnetic signals recorded during a ripple-fired explosion at Gold Quarry, Carlin Nevada, on May 9, 1995. The top three traces are the magnetic field, the bottom two are electric field. The east-directed electric field sensor (Ee) was inoperative at the time of the recording. The signals seen on the traces are due to arrival of ground motion at the sensors. 


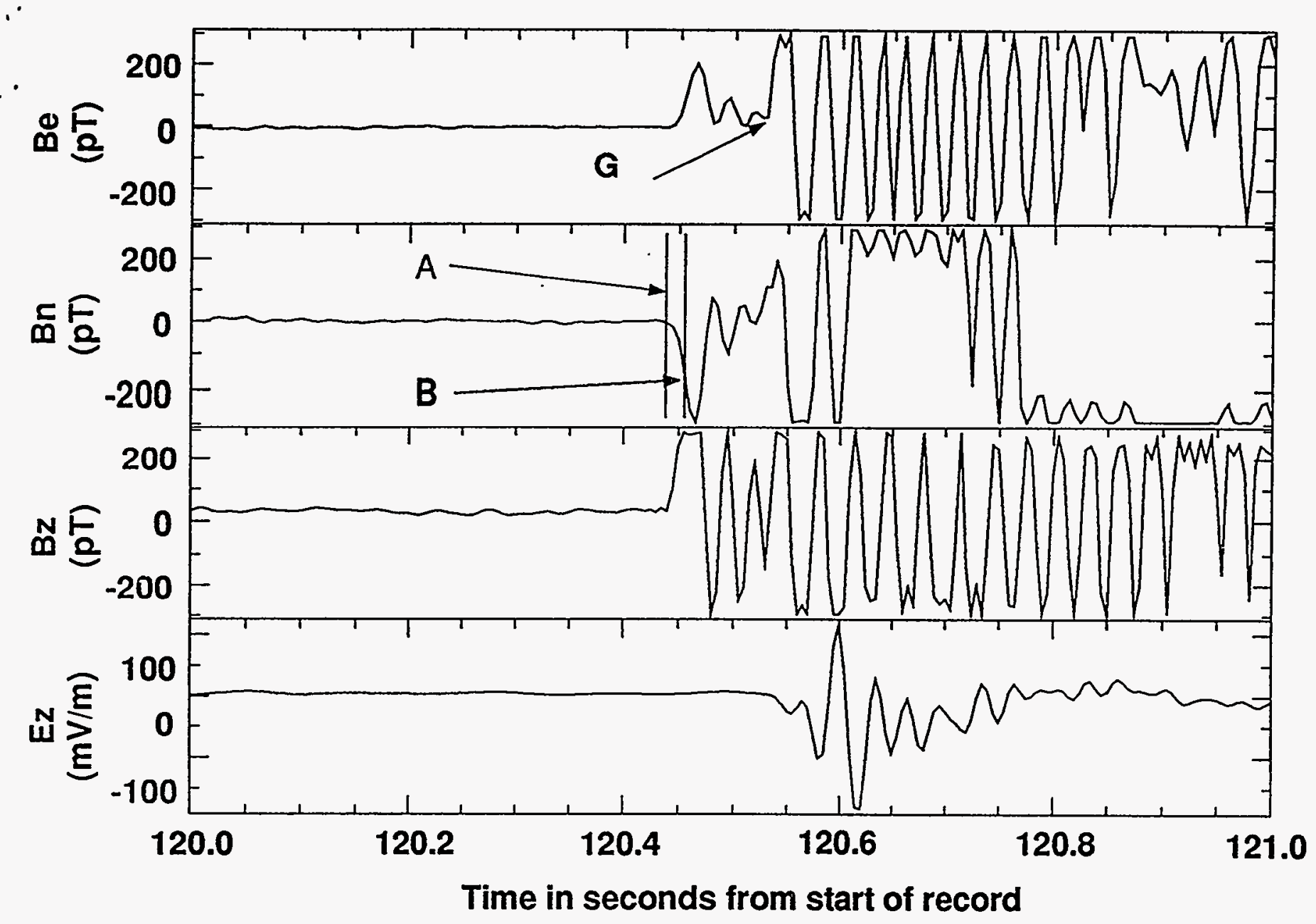

Figure 9. Data from the Kuchen $100 \mathrm{lb}$ explosion on June 22, 1995. The top three traces are east, north, and vertical magnetic field, respectively. The lower trace is vertical electric field. Actual detonation of the chemical explosion was at 0600:00:072 local time (B). The difference in the start of the trace at 0600:00:062 (A) and actual detonation (B) may be due to timing errors in the data acquisition system (see text). The time difference between $A$ and the probable arrival of ground motion (G) is $85 \mathrm{~ms}$, consistent with the nearby seismometer record. 